\title{
New relationship to describe the rheology of sunflower oil
}

\author{
Ioana STANCIU \\ Department of Chemistry, University of Bucharest, 4-12 Regina Elisabeta Blvd., Bucharest 030018, Romania
}

\begin{abstract}
This paper proposes two new relations of dependence of log dynamic viscosity depending on log absolute temperature shear rates between 3.3 and $120 \mathrm{~s}^{-1}$. The constants $\mathrm{A}, \mathrm{B}$, and $\mathrm{C}$ were determined by Origin 6.0 software by fitting linear or polynomial curves obtained from experimental data. The two proposed relationships give correlation coefficients close to one.
\end{abstract}

Keywords: relationship, dynamic viscosity, sunflower oil

\section{Introduction}

In the food industry, viscosity is one of the most important parameters required in designing the technological process. On the other side, viscosity is also an important factor that determines the overall of the system stability $[1,2]$.

Two, three and multi-constant formula have been proposed for the representation of liquid viscosity as a function of temperature by numerous researchers [4, 6]. Giap derived an equation to replace the well-known Arrhenius-type relationship. He used six vegetable oils to test his model and to prove its accuracy [3]. A functional form describing the effect of temperature (t) in ${ }^{\circ} \mathrm{C}$ on liquid viscosity $(\eta)$ in $\mathrm{cP}$ was proposed by Thorpe [4]. Threeconstant form to describe liquid viscosity as a function of temperature was proposed by De Guzman [15]. A three-constant representation was also proposed by Vogel [15]. In addition, a polynomial form was proposed by Reid [2, 6, 14]. A new formula to represent the dynamic viscosity data as a function of temperature was utilized by Danner $[2,8,13]$. Abramovic used modified versions of the Andrade equation to describe the dependence of dynamic viscosities of some of vegetable oils on temperature [2, 5, 9]. In addition, Abramovic suggested new forms to represent the dynamic viscosity data as a function of temperature which has been also used by several investigators [2, 7, 9 - 12].
Two-constant formulas describing the effect of temperature on dynamic viscosity were proposed by Abramovic:

$$
\begin{aligned}
& \log \eta=A / T-B \\
& \eta=A-B \log t
\end{aligned}
$$

where $\eta$ is the dynamic viscosity in $\mathrm{cP}, \mathrm{T}$ is the temperature in $\mathrm{K}, \mathrm{t}$ is the temperature in degrees Celsius. A and B from equations (1) and (2) are constants. Abramovic presented the values of these constants for olive oil [11-16].

Sunflower oil is a non-volatile oil obtained by compressed from sunflower (Helianthus annuus) seeds. Sunflower oil contains predominantly trialkylesters $(48-70 \%)$ of the following acids: oleic (14-40\%), palmitic (4-9\%) and stearic (1-3\%) [1, $2]$. Depending on the fatty acid profiles, sunflower oil is classified as high linoleic ( $>=69 \%$ linoleic acid), high oleic ( $>=82 \%$ oleic acid) and mid oleic respectively. The sunflower oil viscosity decreases with increasing temperature, shear rate and composition.

The variation in the unsaturated fatty acids profile is strongly influenced by both genetics and climate. This paper proposes two new mathematical relationships to study the rheological behavior of sunflower oil. Parameters equations and correlation coefficients were determined with an error of $\pm 1 \%$. The purpose of this study was to find a linear or polynomial dependence between temperature and 
logarithm dynamic viscosity of sunflower oil using Andrade equation changes. Equation constants A, B and $\mathrm{C}$ were determined by fitting linear or polynomial.

\section{Experimental}

Sunflower oil is liquid at room temperature and has the following characteristics: smoke point (refined): $232{ }^{\circ} \mathrm{C}$, smoke point (unrefined): $227{ }^{\circ} \mathrm{C}$, density $\left(25^{\circ} \mathrm{C}\right): 917 \mathrm{~kg} / \mathrm{m}^{3}$, refractive index $\left(25^{\circ} \mathrm{C}\right)$ : $1.473[3,4]$.

The rheological behaviour of sunflower oil was determined using a Haake VT 550 Viscotester developing shear rates ranging between 3 and 1312 $\mathrm{s}^{-1}$ and measuring viscosities from $10^{4}$ to $10^{6} \mathrm{mPa}$.s when the $\mathrm{HV}_{1}$ viscosity sensor is used. The temperature ranging was from 313 to $363 \mathrm{~K}$ and the measurements were made from 10 to 10 degrees.

The accuracy of the temperature measurement was $\pm 0.1^{\circ} \mathrm{C}$.

\section{Results and Discussions}

Figure 1 shows dependency of the log dynamic viscosity on the $\log \mathrm{T}$ for studied sunflower oil at shear rate $3.3 \mathrm{~s}^{-1}, 6 \mathrm{~s}^{-1}, 10.6 \mathrm{~s}^{-1}, 17.87 \mathrm{~s}^{-1}, 30 \mathrm{~s}^{-1}, 52.95 \mathrm{~s}^{-}$ ${ }^{1}, 80 \mathrm{~s}^{-1}$ and $120 \mathrm{~s}^{-1}$.

This study proposes two correlations (Eq.3 and 4) $\log$ dynamic viscosity according to the $\log$ temperature absolute for sunflower oil. We used the computer program Origin 6.0 to determine the constants $\mathrm{A}, \mathrm{B}$ and $\mathrm{C}$ and the correlation coefficients, $R^{2}$. The values of constants $A, B$ and C were determined by fitting linear or polynomial curves obtained for sunflower oil.

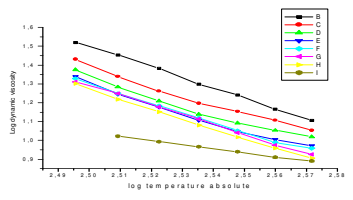

Fig.1. The correlation log dynamic viscosity on the $\log$ absolute temperature at: $\mathrm{B}-3.3 \mathrm{~s}^{-1}, \mathrm{C}-6 \mathrm{~s}^{-1}, \mathrm{D}-$ $10.6 \mathrm{~s}^{-1}, \mathrm{E}-17.87 \mathrm{~s}^{-1}, \mathrm{~F}-30 \mathrm{~s}^{-1}, \mathrm{G}-52.95 \mathrm{~s}^{-1}, \mathrm{H}-$ $80 \mathrm{~s}^{-1}$ and $\mathrm{I}-120 \mathrm{~s}^{-1}$

$$
\begin{gathered}
\log \eta=A+B \log T \\
\text { and } \\
\log \eta=A+B \log T+C(\log T)^{2}
\end{gathered}
$$

The dependency of log dynamic viscosity on the $\log$ absolute temperature for sunflower oil at shear rate $3.3 \mathrm{~s}^{-1}, 30 \mathrm{~s}^{-1}, 52.95 \mathrm{~s}^{-1}$ and $80 \mathrm{~s}^{-1}$ (the black curves from Fig. 2, 3, 4 and 5) was fitting linear as shown in figures 2, 3, 4 and 5. The linear dependence of $\log$ dynamic viscosity on the log absolute temperature for sunflower oil at $3.3 \mathrm{~s}^{-1}$ is described for equation (3):

$$
\log \eta=15.3094-5.5233 \log T
$$

where $\mathrm{A}=15.30938$ and $\mathrm{B}=-5.5233$. The correlation coefficient is $\mathrm{R}^{2}=0.9994$.

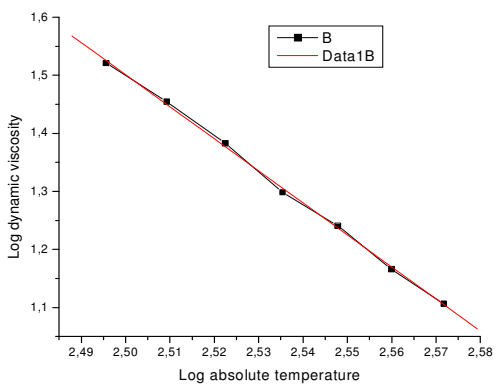

Fig.2. The correlation log dynamic viscosity on the $\log$ absolute temperature at $3.3 \mathrm{~s}^{-1}$ for right to $\mathrm{B}$ and $1 \mathrm{~B}$ represents the linear fitting to $\mathrm{B}$

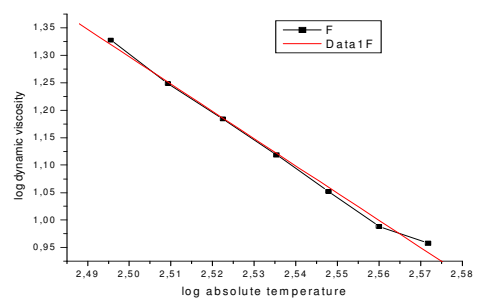

Fig. 3. The correlation log dynamic viscosity on the $\log$ absolute temperature at $30 \mathrm{~s}^{-1}$ for right to $\mathrm{F}$ and $1 \mathrm{~F}$ represents the linear fitting to $\mathrm{F}$ 


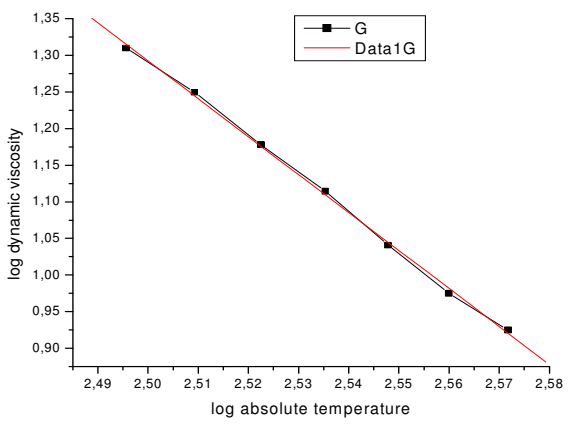

Fig. 4. The correlation log dynamic viscosity on the $\log$ absolute temperature at $52.95 \mathrm{~s}^{-1}$ for right to $\mathrm{G}$ and $1 \mathrm{G}$ represents the linear fitting to $\mathrm{G}$

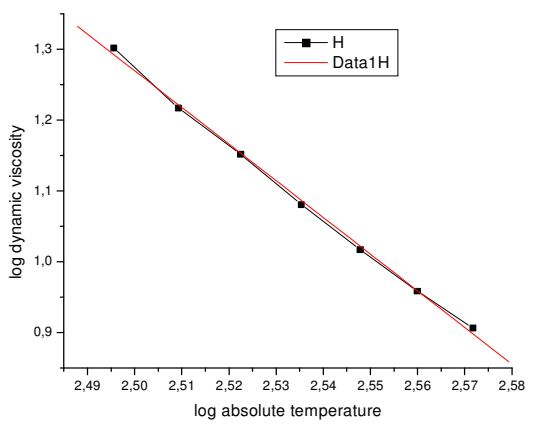

Fig. 5. The correlation log dynamic viscosity on the $\log$ absolute temperature at $80 \mathrm{~s}^{-1}$ for right to $\mathrm{H}$ and $1 \mathrm{H}$ represents the linear fitting to $\mathrm{H}$

Table 1 shows the value of parameters of the described by equation (3) sunflower oil and correlation coefficient, $\mathrm{R}^{2}$. As shown in Table 1 parameter A decreases with increasing shear rate, the parameter B has values close all shear rates and correlation coefficients are close to unity. The root mean square error means that experimental data is spread equation.

The dependency of log dynamic viscosity on the $\log$ absolute temperature for sunflower oil at shear rate $3.3 \mathrm{~s}^{-1}$ and $52.95 \mathrm{~s}^{-1}$ (the black curves from Fig. 6 and 7) was fitting polynomial as shown in figures 6 and 7. The polynomial dependence of natural $\log$ dynamic viscosity on the absolute temperature for sunflower oil at $3.3 \mathrm{~s}^{-1}$ is described for equation (4): $\log \eta=7.7968+0.4074 \log T-1.17035(\log T)^{2}$

where $\mathrm{A}=7.7968, \mathrm{~B}=0.4074$ and $\mathrm{C}=-1.1706$. The correlation coefficient is $\mathrm{R}^{2}=0.9988$.

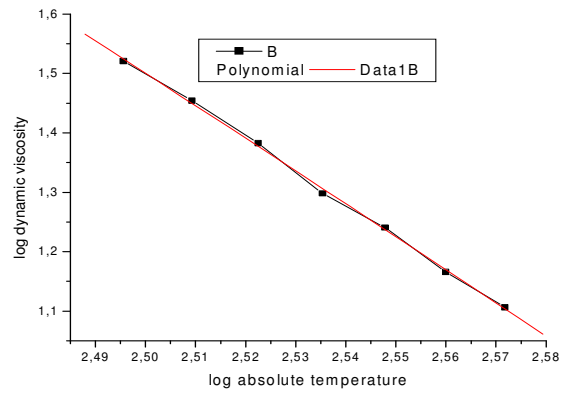

Fig.6. The correlation log dynamic viscosity on the $\log$ absolute temperature at $3.3 \mathrm{~s}^{-1}$ for curve to $\mathrm{B}$ and $1 \mathrm{~B}$ represents the fitting polynomial to $\mathrm{B}$

Table 2 shows the value of parameters of the described by equation (4) sunflower oil and correlation coefficient, R. As Table 2 shows correlation coefficients are close to unity at all shear rates.

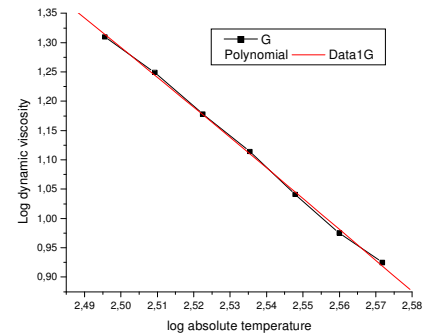

Fig.7. The correlation log dynamic viscosity on the $\log$ absolute temperature at $52.95 \mathrm{~s}^{-1}$ for curve to $\mathrm{G}$ and $1 \mathrm{G}$ represents the fitting polynomial to $\mathrm{G}$ 
Table 1. The shear rate, value of parameters of described by equation (3) and coefficient correlation for sunflower oil

\begin{tabular}{|c|c|c|c|}
\hline \multirow{2}{*}{$\begin{array}{l}\text { Shear } \\
\text { rate, } \mathrm{s}^{-1}\end{array}$} & \multicolumn{2}{|c|}{ Value of parameters } & \multirow{2}{*}{$\begin{array}{c}\text { Correlation } \\
\text { coefficient, } \\
\mathrm{R}^{2}\end{array}$} \\
\hline & $\mathrm{A}$ & B & \\
\hline 3.3 & 15.3094 & -5.5233 & 0.9994 \\
\hline 6 & 13.4182 & -4.8126 & 0.9933 \\
\hline 10.6 & 12.9419 & -4.6455 & 0.9881 \\
\hline 17.87 & 13.4085 & -4.8456 & 0.9922 \\
\hline 30 & 13.7182 & -5.1789 & 0.9993 \\
\hline 52.95 & 14.2397 & -5.1789 & 0.9993 \\
\hline 80 & 14.2225 & -5.1811 & 0.9990 \\
\hline 120 & 6.3841 & -2.1369 & 0.9993 \\
\hline
\end{tabular}

Table 2. The shear rate, value of parameters of described by equation (4) and coefficient correlation for sunflower oil

\begin{tabular}{|c|c|c|c|c|}
\hline \multirow{2}{*}{$\begin{array}{c}\text { Shear } \\
\text { rate, } \\
\mathrm{s}^{-1}\end{array}$} & $\mathrm{~A}$ & $\mathrm{~B}$ & $\mathrm{C}$ & $\begin{array}{c}\text { Correlation } \\
\text { coefficient, } \\
\mathrm{R}^{2}\end{array}$ \\
\hline 3.3 & 7.7968 & 0.4074 & -1.1704 & 0.9988 \\
\hline 6 & 163.0286 & -122.9203 & 23.3072 & 0.9979 \\
\hline 10.6 & 222.6107 & -170.1653 & 32.6635 & 0.9997 \\
\hline 17.87 & 187.6299 & -142.3819 & 27.1413 & 0.9995 \\
\hline 30 & 90.8709 & -65.8753 & 12.01932 & 0.9978 \\
\hline 52.95 & 2.1586 & 4.3584 & -1.8821 & 0.9987 \\
\hline 80 & 75.2938 & -53.3929 & 9.5141 & 0.9997 \\
\hline 120 & 20.6218 & -13.34646 & 2.2062 & 0.9991 \\
\hline
\end{tabular}

\section{Conclusions}

The dynamic viscosity of sunflower oil was determined at temperatures between 313 and $373 \mathrm{~K}$ and shear rates between $3.3 \mathrm{~s}^{-1}$ and $120 \mathrm{~s}^{-1}$. This paper proposes two new correlation log dynamic viscosity to the $\log$ absolute temperature. The values of constants $\mathrm{A}, \mathrm{B}$ and $\mathrm{C}$ and the correlation coefficients were determined by linear and polynomial fitting of the experimental curves using Origin 6.0 software. The correlation coefficients prove a good fitting between experimental and predicted values.

\section{References}

* E-mail address: istanciu75@yahoo.com

[1]. P. Neelamegam and S. Krishnaraj, Indian Journal of Chemical Technology. 18(6), 463 (2011).

[2]. H. Tajweed Nierat, S.M. Musameh and R. Issam Abdel-Raziq, J. Mater. Environ. Sci. 5(1), 245 (2014).

[3]. S.G.E. Giap, J. Phy. Sci., 21(1), 29 (2010).

[4]. T.E. Thorpe, J.W. Rodger and R.E. Barnett, Phil. Trans. 189, 71 (1987).

[5]. A.E. Sterpu, A.I. Dumitru and M.F. Popa, Ovidius University Annals of Chemistry 23(2), 133 (2012).

[6]. J. De Guzman, Anales Soc. Espan. Fis. Y.Quim. 11, 353 (1913).

[7]. H. Vogel, Physics. 22(645-646), 353 (1921).

[8]. R.C. Reid, J.M. Prausnitz and B.E. Poling, Properties of gases and liquids, McGraw-Hill, New York, 4th Ed. (1987).

[9]. T.E. Daubert and R.P. Danner, Physical and thermodynamic properties of pure chemicals data compilation design institute for Physical properties data, AIChE, Taylor and Francis, Washington DC (1994).

[10]. E.N.C. Andrade, Nature, 125, 309 (1930).

[11]. H. Abramovic and G. Klofutar, Acta Chim. Slov, 45(1), 69 (1998).

[12]. M.A. Rao, Rheology of fluid and semisolid foods: principles and applications, Aspen Publishers, Inc., Gaithersburg, Maryland (1999).

[13]. S. Calligaris, S. Sovrano, L. Manzocco and M.C. Nicoli, J. Agric. Food Chem., 54(2), 529 (2005).

[14]. I. Stefanescu, L.C. Solea, G. Zgherea, G. Chirita, C. Spanu, The Annals of University „Dunarea de Jos”' of Galati, VIII(1), 41 (2009).

[15]. D.A. White, I.D. Fisk, J.R. Mitchell, B. Wolf, S.E. Hill and D.A. Gray, Food Hydrocolloids, 22(7), 1224 (2008).

[16]. J. Kim, D.N. Kim, S.H. Lee, S.H. Yoo and S. Lee, Food chemistry, 118(2), 398 (2010).

Submitted: March $15^{\text {th }} 2014$ Accepted in revised form: May $10^{\text {th }} 2014$ 